\title{
The Split-Face Comparison of the Combined Er-YAG Laser and Hydroquinone $4 \%$ With Hydroquinone $4 \%$ Alone in the Treatment of Melasma in Iranian Patients: A Prospective, Interventional Case Study
}

\author{
Nastaran Namazi, Aida Hesami, Yasaman Ketabi* ${ }^{*(D)}$ \\ Skin Research Center, Shahid Beheshti University of Medical Sciences, Tehran, Iran
}

\author{
*Correspondence to \\ Yasaman Ketabi, MD: \\ Resident of Dermatology, Skin \\ Research Center, Shahid Beheshti \\ University of Medical Sciences, \\ Tehran, Iran. \\ Tel: (98) 21-22741507 \\ Fax: (98) 21-22744393 \\ Email: \\ yasamanketabi@gmail.com
}

Published online January 18 , 2020

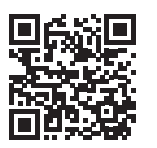

\begin{abstract}
Introduction: Melasma is one of the most common skin pigmentation disorders, which mostly affects the facial skin and has a considerable psychological impact on the patients. Melasma management has been one of the controversial issues in dermatology. We aimed to compare the combined treatment of the Er: YAG (erbium: yttrium-aluminum-garnet) laser plus hydroquinone (HQ) $4 \%$ with HQ $4 \%$ alone in the treatment of melasma.

Methods: Twenty-nine patients were treated with the combined Er: YAG laser and HQ 4\% on one side of the face with $\mathrm{HQ} \mathrm{4 \%}$ alone on the other side. Three sessions of the laser rat 4-week intervals. The outcome was calculated using the Melasma Area Severity Index (MASI).

Results: The side that received the combined treatment (laser + HQ 4\%) showed a statistically significant reduction in MASI compared to the side treated with HQ $4 \%$ alone.

Conclusion: Our study suggests the superiority of the combination of the Er: YAG laser and HQ 4\% in the treatment of melasma compared to $\mathrm{HQ} 4 \%$ alone.

Keywords: Melasma; Hydroquinone; Er: YAG laser.
\end{abstract}

\section{Introduction}

Melasma is a dysfunction of the melanogenesis system, which results in localized, chronic hypermelanosis. ${ }^{1,2}$ It mostly affects women aged between 30 and 55 and appears symmetrically on areas that are exposed to the sun, such as the cheeks, forehead, temples, upper lip and chin. ${ }^{2}$ The exact cause is not clear but genetics, sex hormones, and ultraviolet exposure are proposed to be involved in the pathogenesis of the disease. ${ }^{3}$

Lesions are mostly light brown to blackish patches with irregular borders. ${ }^{2}$ Four types of diseases including epidermal, dermal, mixed epidermal-dermal, and indeterminate have been defined. ${ }^{4}$

Current treatments for melasma are unsatisfactory. Conventional treatments include strict sun protection, lightening agents, chemical peeling, lasers, and various light therapies. To achieve better results in the treatment of melasma, it has been proposed that the topical application of skin lightening agents could be combined with the procedures that enhance the skin penetration of the drugs, such as electroporation and micro-needling.

The utilization of lasers for enhancing drug delivery was described in 1987 using ablative non-fractional device lasers. It has been proposed that various types of lasers improve drug penetration by three mechanisms: (1) tissue ablation, which removes the stratum corneum and the most superficial layers of the epidermis; (2) photomechanical waves, resulting from the conversion of light into mechanical energy; and (3) non-ablative resurfacing, where thermal and physical injuries rupture the skin barrier, promoting the delivery of medications.

The Er: YAG (erbium: yttrium-aluminum-garnet) laser contains $2940 \mathrm{~nm}$ wavelength of the light which is absorbed by tissues containing water ${ }^{4}$ and could be useful in melasma treatment with minimal thermal damage and post-inflammatory hyperpigmentation. ${ }^{4}$ In a previous study, Attwa et al reported the YAG laser as an effective treatment for melasma. ${ }^{5}$

This study, we aimed to compare the treatment effect of the combination of the Er: YAG laser and HQ with HQ alone in the management of facial melasma.

\section{Materials and Methods}

This prospective study was conducted in Shohada-eTajrish hospital between March 2016 and December 2016. Twenty-nine female patients who had bilateral

Please cite this article as follows: Namazi N, Hesami A, Ketabi Y. The split-face comparison of the combined Er-YAG laser and hydroquinone $4 \%$ with hydroquinone $4 \%$ alone in the treatment of melasma in Iranian patients: A prospective, interventional case study. J Lasers Med Sci. 2020;11(1):70-73.doi:10.15171/jlms.2020.12. 
facial melasma and Fitzpatrick skin types III-V were recruited, and their ages ranged from 18 to 45 . The baseline characteristics of the patients, including age, skin Fitzpatrick type, history of the pregnancy, and OCP consumption were recorded. Examination using Wood's lamp determined the types of lesions (epidermal, dermal, and mixed) (Table 1).

Exclusion criteria were the recent use of depigmenting agents, pregnancy, autoimmune diseases, the concomitant use of isotretinoin or hormonal therapy, thyroid disease, cutaneous infection/inflammations, and ectropion.

The institutional review board approved the project and all cases were asked to fill informed consent forms. The study had also been approved by the local ethics committee.

One side of the face was randomly selected for laser therapy and it was cleaned by alcohol completely one hour before laser application. Then topical anesthetic cream (EMLA; AstraZeneca, Sodertalje, Sweden) was applied and hair-bearing areas were covered with damp towels. The Er: YAG (Fotona; skin plus surgical laser system model $220 \mathrm{~A}$ ) was calibrated to $1.0 \mathrm{~J}$ with a $5 \mathrm{~mm}$ collimated spot at $5 \mathrm{~Hz}$ and applied once vertically and once horizontally. Three monthly laser sessions $(0,4,8$, weeks) were conducted consecutively and the patients were recommended to use HQ 4\% nightly on both sides of the face during 5 to 80 days after laser treatment.

The patients were evaluated in $0,4,8,28$ weeks and underwent a dermatologic examination by a dermatologist to evaluate the efficacy and safety of the treatment and also the participants' satisfaction. Further,

Table 1. Basic Characteristics of Participants

\begin{tabular}{lc}
\hline Variables & $36.1 \pm 8$ \\
\hline Age $(y)$ & \\
Location & $17(58.6 \%)$ \\
Right & $12(41.4 \%)$ \\
Left & \\
Type & $16(55.2 \%)$ \\
Epidermal & $8(27.6 \%)$ \\
Dermal & $5(17.2 \%)$ \\
Mixed & \\
Fitzpatrick & $10(34.5 \%)$ \\
II & $9(31 \%)$ \\
III & $10(34.5 \%)$ \\
IV & \\
History of OCP consumption & $11(37.9 \%)$ \\
Yes & $11(37.9 \%)$ \\
No & $18(62.1 \%)$ \\
Nistory of Pregnancy & \\
\hline & \\
\hline & \\
No & \\
\hline
\end{tabular}

2 blinded dermatologists calculated the MASI based on photographs according to the standard formula. The total MASI score is as follows: Forehead $0.3(\mathrm{D}+\mathrm{H}) \mathrm{A}+$ right malar $0.3(\mathrm{D}+\mathrm{H}) \mathrm{A}+$ left malar $0.3(\mathrm{D}+\mathrm{H}) \mathrm{A}+$ chin 0.1 $(\mathrm{D}+\mathrm{H}) \mathrm{A}^{6}$ in which darkness $(\mathrm{D})$ homogeneity $(\mathrm{H})$ and areas (A) are involved and the degree of involvement of each facial area is shown as percentage (10\%-30\%).

All lesions were photographed by using the iPhone photographic system.

Since one of the consequences of the different therapeutic interventions in hemi-split faces is asymmetric changes of the skin, we considered to apply additional laser and HQ treatment to bleach the darker side, if the patients complained of significant differences between two sides, which remained after 52 weeks.

Statistical Analysis

Data analysis was conducted by using SPSS software version 22 (IBM, Chicago, IL, USA). We used a chi-square test with Fisher exact test and an independent-samples $t$ test for categorical and continuous data respectively. $P$ value significance was considered 0.05 for all statistical tests.

\section{Results}

Twenty-nine cases were enrolled in the present study. The baseline characteristics of the patients are shown in Table 1.

The mean MASI scores were not significantly different between two groups at the baseline (laser side: $17.64 \pm 8.21$; another side: $18.43 \pm 8.62 ; P=0.07$ ), but after 8 weeks the laser side had a lower MASI score in comparison to HQ. In week 28 , there was still a difference between the MASI scores of the two sides, although with no statistical significance (Table 2). No patients complained of an asymmetric look during the study and in week 52 . Figure 1 reveals the different pigmentation levels of both treatment modalities.

Five patients in this study developed post-inflammatory hyperpigmentation and recurrence was found in 6 $(20.6 \%)$ cases.

\section{Discussion}

This study was conducted to evaluate the effect of the Er: YAG laser plus HQ in comparison to HQ alone on the treatment of facial melasma.

Several studies evaluated the efficacy of lasers in the

Table 2. Mean MASI Scores in Patients

\begin{tabular}{llll}
\hline & Laser Side & Another Side & $\boldsymbol{P}$ Value \\
\hline At the beginning & $17.64 \pm 8.21$ & $18.43 \pm 8.62$ & 0.07 \\
4th week & $5.15 \pm 3.35$ & $7.84 \pm 3.35$ & 0.003 \\
8th week & $4.74 \pm 2.86$ & $9.75 \pm 4.64$ & 0.0001 \\
28th weak & $8.35 \pm 4.87$ & $10.82 \pm 5.95$ & 0.0891 \\
\hline
\end{tabular}



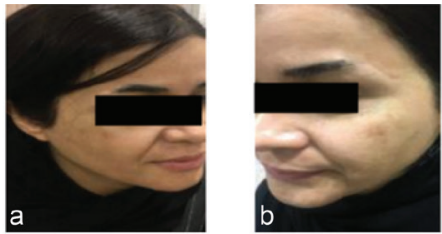

First session
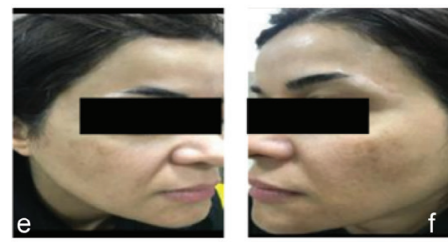

Third session (8th week)

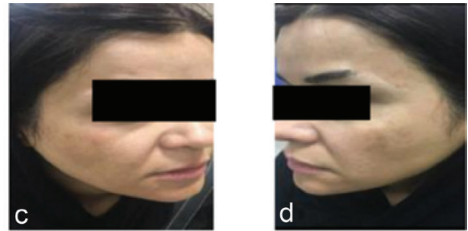

Second session (4th week)
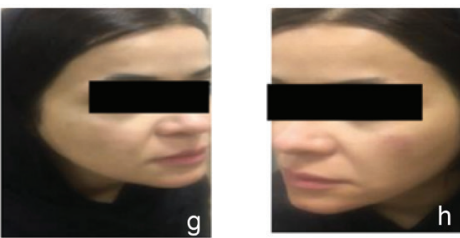

Last session (28th week)

Figure 1. $(c, e, g)$ Laser and Hydroquinone; $(d, f, h)$ Hydroquinone Alone.

treatment of melasma. Because of the barrier effect of the stratum corneum on the penetration of topical medication, some modalities like iontophoresis-micro needling have been developed to enhance drug delivery to the skin. ${ }^{6}$ As previously reported, one of the known side effects of laser treatment is PIH which can diminish the treatment effect. However, because of the lower pulse duration of the Er: YAG laser in comparison with the thermal relaxation time of skin, it produces lower heat dissipation and shorter healing time and consequently lower risk of PIH., ${ }^{7,8}$ In one study, 10 females with refractory melasma were treated with the Er: YAG laser and significant improvement was reported immediately, but all of the patients developed PIH. ${ }^{6}$ In our study, 5 patients (20\%) had PIH following laser treatment, which should be considered as a common complication of this treatment.

Melasma recurrence after the Er: YAG laser is an issue that may have an impact on the efficacy of treatment. Gokalp et al applied the Er: YAG laser for 34 patients with melasma; despite the short-term efficacy of the treatment, $58 \%$ of the patients complained of recurrence after 1 year. In our study, 6 patients reported a recurrence of melasma at the end of the study, so longer follow-ups and larger studies are required to assess the durability and stability of this treatment modality. ${ }^{9}$

This study showed that the combination of the Er: YAG laser and HQ in the treatment of melasma was more effective and durable than HQ alone (Table 2), but after 28 weeks it lost its significance. Therefore, one of the disadvantages of YAG laser treatment is the need for continuous treatment (monthly), which may lead to patients' withdrawal.

The study was potentially limited by the small size of the study. In addition, due to the limited number of the participants, it was not possible to perform subgroup analysis according to the baseline characteristics. Another limitation refers to the short time of follow-up, which seems to be insufficient to evaluate the long-term efficacy and safety of the treatment. Therefore, larger studies are warranted to assess the efficacy and possible complications of the Er: YAG laser in the treatment of melasma.

\section{Ethical Considerations}

In this study all the participants understood and signed the informed written consent, and also the Ethical Committee approved the experiments.

\section{Conflict of Interests}

The authors declare no conflict of interest.

\section{Acknowledgment}

This study was supported financially by Skin Research center, Shahid Beheshti University of Medical Sciences.

\section{References}

1. Handel AC, Miot LD, Miot HA. Melasma: a clinical and epidemiological review. An Bras Dermatol. 2014;89(5):771-82. doi: 10.1590/abd1806-4841.20143063.

2. Morais OO, Lemos ÉF, Sousa MC, Gomes CM, Costa IM, Paula CD. The use of ablative lasers in the treatment of facial melasma. An Bras Dermatol. 2013;88(2):238-42. doi: 10.1590/S0365-05962013000200009.

3. Tamega Ade A, Miot LD, Bonfietti C, Gige TC, Marques ME, Miot HA. Clinical patterns and epidemiological characteristics of facial melasma in Brazilian women. J Eur Acad Dermatol Venereol. 2013;27(2):151-6. doi: 10.1111/j.1468-3083.2011.04430.x.

4. Manaloto RM, Alster T. Erbium: YAG laser resurfacing for refractory melasma. Dermatol Surg. 1999;25(2):121-3. doi: 10.1046/j.1524-4725.1999.08103.x.

5. Attwa E, Khater M, Assaf M, Haleem MA. Melasma treatment using an erbium: YAG laser: a clinical, immunohistochemical, and ultrastructural study. Int $J$ Dermatol. 2015;54(2):235-44. doi: 10.1111/ijd.12477.

6. Fabbrocini G, De Vita V, Fardella N, Pastore F, Annunziata 
MC, Mauriello MC, et al. Skin needling to enhance depigmenting serum penetration in the treatment of melasma. Plast Surg Int. 2011. doi: 10.1155/2011/158241.

7. Alster TS. Clinical and histologic evaluation of six erbium: YAG lasers for cutaneous resurfacing. Lasers Surg Med. 1999;24(2):87-92. doi: 10.1002/(sici)10969101(1999)24:2<87::aid-lsm3>3.0.co;2-p.

8. Hohenleutner U, Hohenleutner S, Bäumler W, Landthaler
M. Fast and effective skin ablation with an Er: YAG laser: determination of ablation rates and thermal damage zones. Lasers Surg Med. 1997;20(3):242-7. doi: 10.1002/ (sici)1096-9101(1997)20:3<242::aid-1sm2>3.0.co;2-q.

9. Gokalp H, Akkaya AD, Oram Y. Long-term results in low-fluence 1064-nm Q-Switched Nd: YAG laser for melasma: Is it effective? J Cosmet Dermatol. 2016;15(4):420-26. doi: 10.1111/jocd.12253. 